\title{
Venezuela: once años de gestión de Hugo Chávez Frías y sus fuerzas bolivarianas (1999-2010)
}

\author{
Venezuela: the eleven years administration of Hugo Chávez Frías and his bolivarian \\ forces (1999-2010)
}

\section{Margarita López Maya}

\author{
Margarita López Maya es profesora titular del Centro \\ de Estudios del Desarrollo (CENDES) de la Universidad \\ Central de Venezuela, Venezuela. \\ E-mail: malopezmaya@yahoo.com
}

\section{resumen}

En diciembre de 1998, con el triunfo electoral de Hugo Chávez Frías y su alianza, el Polo Patriótico, comenzó en Venezuela un proceso de cambios que dura hasta hoy y se inició también en América latina, lo que algunos denominan el giro a la izquierda de la región. Chávez se impuso durante la campaña presidencial mediante un fuerte discurso polarizador y anti-neoliberal, que prometió desplazar definitivamente a las elites políticas, que dominaban el Estado desde hacía décadas, acabar con la corrupción administrativa y encontrar a través de una democracia participativa, un nuevo modelo económico y político para el país. En este artículo pasamos revista a las gestiones gubernamentales de Hugo Chávez hasta hoy distinguiendo dos períodos de características diferenciadas: su primer gobierno orientado por la democracia participativa y protagónica; y el segundo período actualmente en curso, orientado por un proyecto denominando Socialismo del siglo XXI.

\section{palabras clave}

Venezuela / gobierno de Chávez / democracia participativa / socialismo del siglo XXI

\section{keywords}

Venezuela / Chávez government / participative democracy / twenty first century socialism
The electoral triumph of Hugo Chávez Frías and his alliance -Polo Patriótico- gave rise to a change process which began in December 1998 and is still in force in Venezuela. This so-called turn to the left also developed in the rest of Latin America. The strong, polarizing and anti-neoliberal discourse of Chávez during his presidential campaign proposed the definitive removal of the state's dominant political elites which had prevailed for many decades; the elimination of the administrative corruption; and, the achievement of a new political pattern for the country through a participative democracy. The review of the governmental actions of Chávez in this article draws a distinction between his first administration which was oriented towards a participative leading democracy; and, the second on-going one which is oriented towards a project known as Twenty First Century Socialism. 
En diciembre de 1998, con el triunfo electoral de Hugo Chávez Frías y su alianza, el Polo Patriótico, comenzó en Venezuela un proceso de cambios que dura hasta hoy. Con este triunfo se inició también en América latina, lo que algunos denominan el giro a la izquierda de la región (Levitsky y Roberts, 2010). Chávez se impuso durante la campaña por la presidencia mediante un fuerte discurso polarizador y anti-neoliberal, que prometió desplazar definitivamente a las elites políticas que dominaban el Estado desde hacía décadas, acabar con la corrupción administrativa y encontrar a través de una democracia participativa, un nuevo modelo económico y político para el país. Venezuela arrastraba una crisis estructural que duraba ya veinte años. El discurso de Chávez fue extraordinariamente exitoso, pues supo expresar el malestar, tanto de los venezolanos como de muchos en el continente, por los desempeños de gobiernos neoliberales de las últimas décadas del siglo. Aún hoy despierta grandes pasiones.

El presidente Chávez lleva once años en el poder, gracias a la aprobación en 1999 por referendo popular de una nueva Constitución -la Constitución de la República Bolivariana de Venezuela (en adelante CRBV)- que aumentó el período presidencial de cinco a seis años permitiendo la reelección inmediata del Presidente por una sola vez. Podrá permanecer incluso indefinidamente, ya que en 2009, por una enmienda constitucional, sometida también a refrendo popular en febrero, se removieron los obstáculos constitucionales para permitir la reelección indefinida del Presidente y todos los cargos de elección popular. En el análisis que aquí haremos de estos años en el poder, nos guiaremos por la tipología de Levitsky y Roberts, que colocan al líder venezolano y su gobierno como "populista de izquierda", el caso más extremo que hasta ahora ha dado la región en los albores del siglo XXI.

A continuación distinguimos dos grandes períodos en la era de Chávez, correspondientes a sus dos periodos constitucionales. El primero va desde febrero de 1999 cuando tomó posesión del cargo de Presidente por primera vez, hasta enero de 2007, cuando se juramentó para un segundo período. El segundo período llega hasta la actualidad. Se trata de dos momentos bien diferenciados, pues en el primero la gestión gubernamental siguió fundamentalmente las orientaciones de la CRBV, buscando construir una institucionalidad acorde a la "democracia participativa y protagónica". El segundo, en contraste, sigue las orientaciones de la propuesta de una reforma constitucional rechazada por el referendo popular realizado en 2007, y busca un "socialismo del siglo XXI", que guarda importantes diferencias y aún contradicciones con la CRBV. Hay una ruptura importante entre ambos períodos. En cada uno buscaremos señalar hechos, políticas y resultados más relevantes.

\section{Gestión del primer gobierno (1999-2007): la lucha hegemónica}

La victoria electoral de Hugo Chávez y el Polo Patriótico en 1998 significó un momento de inflexión en el proceso sociopolítico venezolano. La sociedad, padeciendo una crisis integral sin solución que demoraba ya dos décadas, había visto perderse muchos logros modernizadores alcanzados a lo largo del siglo XX. 
El descontento era generalizado y profundo. En la campaña de ese año por la Presidencia, estaban colocadas las condiciones materiales y anímicas para que los votantes rompieran con el pasado y se pronunciaran por un cambio radical de elites y proyecto político (López Maya, 2005). Chávez y su movimiento, hasta ese momento outsiders y/o marginales de la política venezolana, obtendrían el triunfo electoral al expresar lo que pareció en ese momento ser las aspiraciones de la mayoría: construir una democracia participativa, rechazar las políticas neoliberales y expulsar del poder a los partidos corruptos e insensibles. ${ }^{1}$

En esta parte nos centraremos primero en caracterizar el tipo de gobierno que representa el presidente Chávez y el Polo Patriótico en el contexto latinoamericano actual. Luego examinaremos las orientaciones fundamentales de la CRBV, aprobada en referendo en 1999, que marcaron los cambios del Estado y las relaciones Estado-sociedad en este primer gobierno. En tercer término, analizaremos el rechazo y la confrontación violenta que enfrentó el gobierno por parte de fuerzas opositoras y factores de poder al dar comienzo a los cambios. Esta confrontación la caracterizamos en términos gramscianos como una lucha hegemónica, pues enfrentó dos bloques de actores sociopolíticos con proyectos claramente diferenciados y percibidos como antagónicos. En cuarto lugar, se revisarán los resultados electorales de 2004 y 2005, que prácticamente borraron a las fuerzas opositoras de los espacios institucionales de deliberación y gobierno. Y finalmente, echaremos una mirada gruesa a la gestión social del gobierno, en particular al lanzamiento de las misiones sociales y las diversas variantes de innovaciones participativas.

\section{1. ¿Qué tipo de gobierno es el de Chávez?}

Caracterizamos las gestiones del presidente Chávez dentro del patrón izquierda populista. De acuerdo con Levitsky y Roberts (2010), tiene de izquierda, que tanto en su discurso como en su práctica, prioriza la reducción de las desigualdades sociales y económicas de la población, lo cual es el denominador común de los recientes gobiernos de izquierda en la región. También sus gestiones comparten con la izquierda latinoamericana actual, el énfasis en fortalecer la participación de los más débiles o alejados del poder y socavar formas jerárquicas y discriminatorias de dominación tanto de clase como de género, raza o etnicidad.

Adicionalmente, los gobiernos de Chávez son populistas, entendiendo por ello que promueven desde el Estado un tipo de movilización y organización social y política que sigue una dinámica de arriba hacia abajo y privilegia la figura personalista del líder, que confronta a las elites tradicionales mediante el discurso dicotómico oligarquía-pueblo. Esta definición de populismo no contempla contenidos ideológicos -que han sido muy variados a lo largo de la historia de los populismos latinoamericanos- ciñéndose a estas dimensiones del discurso y la forma de movilización que han sido recurrentes.

\section{La Constitución de la República Bolivariana de Venezuela}

La llegada de los bolivarianos al poder en 1999 se produjo de manera rápida, por lo que muchas de sus propuestas al momento de comenzar a gobernar eran vagas, 
con escasa claridad y consenso sobre las formas de implementación. El Presidente dio prioridad ese año al proceso constituyente, para lograr la elaboración de una nueva constitución, que se aprobó ese diciembre. La Asamblea Constituyente se instaló en julio, y ya para diciembre de ese año, en lo que puede considerarse un proceso acelerado -atropellado- de deliberación, la CRBV fue aprobada en referendo popular. Aunque deficitario, el proceso constituyente tuvo importantes logros en términos de movilizar diversos actores sociopolíticos y asentar muchas de las aspiraciones de cambio, que se estuvieron formulando, debatiendo e incluso practicando en los lustros anteriores, tanto en espacios institucionales como la $\mathrm{COPRE}^{2}$ y algunos gobiernos locales, como en el seno de organizaciones de la sociedad civil y en la lucha callejera (López Maya y Lander, 2001).

Obtuvo centralidad y consenso importante durante las deliberaciones de la Asamblea, la profundización de la democracia para hacerla participativa y protagónica. La CRBV mantuvo la autonomía de los poderes públicos y los instrumentos de la representación política liberal, pero buscando romper la oligarquización que el sistema de partidos generó en el pasado, combinó las instituciones de representación con instrumentos para la participación ciudadana directa y semidirecta, tanto en la toma de decisiones como para la consulta y gestión de políticas públicas. Para ello, se incorporaron cuatro tipos de referendo popular (consultivo, aprobatorio, abrogatorio y revocatorio), iniciativas legislativas, asambleas de ciudadanos y consejos locales de planificación pública entre otras modalidades. El constituyente buscó debilitar la figura de los partidos políticos, omnipresentes y poderosísimos en el régimen anterior. Pasaron a llamarse "organizaciones con fines políticos", un eufemismo que expresó la desconfianza o el rechazo que hacia ellos tenían los nuevos actores. Igualmente, la CRBV prohibió su financiamiento con dineros públicos.

En lo social, la CRBV amplió los derechos humanos para incluir los derechos de los pueblos indígenas a su autodeterminación y al respeto a sus culturas (Capítulo 8), los derechos ambientales (Capítulo 9), el reconocimiento del trabajo del hogar como actividad económica que crea valor agregado y el derecho de las amas de casa a la seguridad social (Artículo 88). Los militares adquirieron el derecho al voto, sin que se les permitiese optar a cargos de elección, ni tener militancia o hacer proselitismo político (Artículo 330). Como reflejo de una debilidad del componente civil en la nueva hegemonía, se sustrajo del parlamento el control de los ascensos militares, que pasaron a ser responsabilidad exclusiva de la institución y del Presidente (Artículo 331).

La CRBV reafirmó la centralidad del Estado presente en la constitución de 1961, lo mismo que la vigencia del principio universal de los derechos sociales y el deber del Estado de crear las condiciones para garantizarlos. También reasentó la propiedad estatal del recurso petrolero (Artículo 303), deteniendo así las tendencias privatizadoras abiertas por la política de Apertura petrolera desarrollada en los años noventa. En lo económico, se respetó la propiedad privada introduciendo dispositivos nuevos para que el Estado impulsase la economía social y reconociese formas de propiedad colectiva. En materia internacional se señalaron 
principios orientadores como la democratización del orden internacional, la integración latinoamericana y la "solidaridad entre los pueblos en la lucha por su emancipación y el bienestar de la humanidad" (Artículos 152 y 153). La CRBV se dio en un contexto latinoamericano inicialmente bastante adverso a estas ideas, donde predominaban enfoques neoliberales de reducción del papel interventor del Estado y privatización de servicios públicos, lo que la hizo ver como muy radical. Sin embargo, la CRBV no significó una ruptura distintiva con la Constitución de 1961. Más bien reflejó ser una continuación de ésta, expresando una propuesta estatista moderada en lo económico, distributiva en lo social, independiente en lo internacional y a medio camino entre la democracia representativa y la directa en sus instituciones democráticas. Tanto en la nueva Carta Magna como en las Líneas Generales de Desarrollo Económico y Social de la Nación 2001-2007 (en adelante LGDESN), que sirvió de orientación a la gestión del primer Gobierno, subyacía una concepción de democracia sustantiva, que el Presidente caracterizó, influenciado por el gobierno británico de Tony Blair, como una "tercera vía" -ni capitalismo ni socialismo-.

\section{La confrontación hegemónica}

A mediados de 2001, las fuerzas sociales y políticas que desde la campaña electoral de 1998 se habían opuesto al proyecto político de cambios, comenzaron a visibilizar su descontento de manera creciente. En diciembre de ese año realizaron su primera protesta masiva y exitosa conocida como el paro cívico del $10 \mathrm{de}$ diciembre, que logró paralizar una parte significativa del comercio urbano, y tuvo el efecto de unir un conjunto de fuerzas de la oposición que hasta ese momento se movían dispersa y fragmentadamente en el espacio político (López Maya, 2002). El paro fue convocado por la Federación de Cámaras de la Industria y el Comercio (Fedecámaras), la principal organización de cámaras empresariales venezolanas. De él emergería como la cabeza de la oposición el presidente de esa confederación empresarial, Pedro Carmona Estanga.

El éxito alcanzado por este paro cívico obedeció a varios factores. En primer lugar, convocó a los grupos descontentos -en Venezuela, pero también en el exterior- con los contenidos de naturaleza nacionalista de la nueva Carta Magna. Inversionistas y la gran mayoría de los grupos económicos venezolanos, vinculados al capital transnacional, particularmente el petrolero, rechazaban el regreso a un Estado con capacidad reguladora de la vida económica y social, la reafirmación de la propiedad estatal del recurso petrolero, el derecho de los trabajadores a prestaciones sociales, entre otros aspectos que fueron reafirmados o incluidos en la CRBV. Cuando en noviembre de 2001 el gobierno, haciendo uso de facultades extraordinarias conferidas por la Asamblea Nacional (AN), dio un paso más en la implementación de los cambios, aprobando por Ley Habilitante, la ley de Tierras, la de Hidrocarburos y la de Pesca, con las cuales profundizaba en procesos de regularización de la propiedad privada, así como en actividades económicas claves como la petrolera, estas fuerzas comenzaron a desarrollar una estrategia sostenida de resistencia y confrontación. 
Además de estos intereses, el Gobierno también contribuyó a crear significativas tensiones con otros actores, debido a una conducción política con errores y en algunos aspectos claramente autoritaria (Parker, 2002). Al aprobar leyes importantes sin difundir y ampliar los espacios para la participación y el debate, el Gobierno hizo aparecer como justa la indignación de quienes se sentían afectados, sin crear las condiciones para que quienes se beneficiaban de tales leyes pudieran enterarse de su contenido y así, defenderlas. Es de señalar que este modo de aprobar leyes de gran potencial de cambio para la sociedad contradecía el contenido de democracia participativa de la CRBV recién sancionada. A esto se añadía el hecho de que, a lo largo de los meses de 2001, el Gobierno fue confrontando, por diversos motivos, con otros sectores sociales y políticos, como el sindicalismo tradicional de la CTV (Ellner, 2003), con sectores de la educación privada y religiosa a los cuales quiso imponer una nueva ley de Educación, con sectores mediáticos que se oponían a cualquier regulación de los medios de comunicación, y con aliados políticos como el partido MAS y el alcalde mayor de Caracas, lo que facilitó la convergencia de las hasta entonces fragmentadas fuerzas de la oposición en una sola plataforma política. Con el éxito del paro cívico del 10 de diciembre, esta plataforma se robusteció. La oposición unida y fortalecida, reconociendo el liderazgo del empresario Carmona, se cerró en diciembre a las negociaciones con el Gobierno y exigió la derogación de todas las leyes aprobadas mediante la Ley Habilitante (49 en total). Algunos grupos ya demandaban la renuncia del presidente Chávez. El Gobierno, por su parte, endureció aún más las posiciones que había sostenido antes del paro, negándose a modificar o ceder en ninguna de sus leyes; amenazó con cerrar la Asamblea Nacional (AN) si perdía la mayoría parlamentaria y con promulgar una ley de medios de comunicación que limitaría la actividad de los medios privados.

$\mathrm{Al}$ iniciarse el año 2002 la atmósfera era de agitada e intensa actividad política. En enero comenzó la febril tarea marchista en el país, que se extendió a todo el año y sólo cedió paulatinamente después del paro petrolero en 2003. Mes tras mes, cada marcha de la oposición fue respondida por una contramarcha de los simpatizantes del Gobierno. Las clases medias y altas bajo el liderazgo de Fedecámaras y de la CTV (la confederación sindical más importante del país), comenzaron a disputarse la calle con los sectores populares liderados por el Presidente y sus fuerzas sociales y políticas (PROVEA, 2002; 2003). Las fuerzas de la oposición constituyeron una organización paraguas que las contenía a todas, que se conocería como la Coordinadora Democrática $(\mathrm{CD})$.

Los hilos que condujeron al golpe de Estado del 11 de abril se fueron tejiendo en esta sostenida política de la calle. El ovillo comenzó a desenrrollarse a partir del nombramiento, en febrero, de una nueva directiva de Petróleos de Venezuela SA (PDVSA) por parte del Ejecutivo Nacional. La gerencia mayor de esta empresa estatal rechazó algunas de las designaciones, argumentando que no se respetaban los tradicionales méritos para tal ascenso. Sin embargo, tras el argumento de la meritocracia se escondían otros motivos. Desde que asumiera la Presidencia, Chávez se fue haciendo evidente la presencia de dos posiciones antagónicas con respecto al rol de la industria petrolera en el futuro de la sociedad. Por una parte, 
entre las fuerzas de la oposición, se respaldaba el proyecto de Apertura petrolera desarrollado en los noventa, pensado desde la gerencia de PDVSA, según el cual la industria debía independizarse del control estatal para ser dirigida por sus altos gerentes (CD, 2003). Esta propuesta priorizaba los aumentos de volúmenes de producción sobre precios, tendía a disminuir el ingreso fiscal petrolero y propendía a una gradual privatización de la industria. En el proyecto de Chávez, en la CRBV y en las leyes aprobadas en 1999 y 2001 (de Hidrocarburos Gaseosos e Hidrocarburos Líquidos respectivamente) se revirtió la política de Apertura, reasegurando el control estatal sobre la industria, privilegiando los pagos de regalías sobre los pagos de impuestos a las ganancias (lo que beneficia al ingreso fiscal) y desarrollando una política de aumentos de precios sobre volúmenes de producción, lo que acercaba de nuevo al país a las estrategias de la OPEP (Lander, 2003).

El 9 de abril la Confederación de Trabajadores de Venezuela (CTV), en solidaridad con el paro de los trabajadores de PDVSA, llamó a un paro laboral general de 24 horas. Ese paro contó con el explícito apoyo de Fedecámaras, la Iglesia Católica (representada por el episcopado venezolano) y organizaciones sociales y políticas de oposición. Pasadas las 24 horas, y aunque el paro estuvo lejos de obtener la contundencia del realizado el 10 de diciembre anterior, la CTV prorrogó por 24 horas más esta huelga. Al día siguiente, y sin que todavía se le viera a dicho paro suficiente fuerza, Carlos Ortega, presidente de la CTV, llamó a la huelga general indefinida y convocó para el día siguiente a una marcha que partiría del Parque del Este, en el este de Caracas, y terminaría en el edificio de PDVSA en Chuao, también en el este de la ciudad. Eran los primeros pasos en la estrategia del golpe de Estado que sucedería esa noche. ${ }^{3}$

La nutrida marcha de la oposición se inició el 11 de abril hacia las 10.00am e hizo su recorrido anunciado. Pero al mediodía, al llegar al edificio de PDVSA en Chuao, los convocantes decidieron arengar a las multitudes para que se dirigiesen al Palacio Presidencial de Miraflores para sacar a Chávez. La marcha, el mensaje y la convocatoria a Miraflores fueron profusamente informados, convocados y cubiertos por los canales privados de televisión, que de esta manera hicieron explícito su apoyo político a lo que era una clara situación insurreccional. La marcha fue creciendo en la medida en que iba hacia el centro de Caracas.

Mientras tanto, el Palacio de Miraflores, ubicado en el oeste de la capital, estaba rodeado de civiles simpatizantes del gobierno que allí hacían vigilia protegiendo al Presidente desde el 9 de abril cuando la CTV anunció el primer paro de 24 horas. Mientras la marcha de la oposición avanzaba, el partido del Gobierno hacía llamados a toda su militancia para que rodearan y protegieran el Palacio. El Presidente encadenó, a las $3.45 \mathrm{pm}$, los medios de comunicación y se dirigió al país buscando ejercer algún control sobre los acontecimientos, mientras las multitudes seguían agolpándose alrededor del Palacio y la marcha opositora creciendo en su camino para sacar a Chávez. La Guardia Nacional rodeó la sede de gobierno, pero al llegar la marcha al centro de Caracas alguien hizo el primer disparo. Los medios pasarían ese y los días siguientes, una y cien veces, lo que ellos dicen fueron francotiradores chavistas que masacraban a civiles antichavistas en puente Llaguno, cerca del 
Palacio. Esto, que resultó ser una manipulación de imágenes por parte de los medios privados, sirvió de justificación para el golpe de Estado. Pocas horas después, aparecieron por los medios de comunicación los pronunciamientos militares de desobediencia, y a las 4.00am del día 12, Chávez salió con su escolta de Miraflores para entregarse preso en el Fuerte Tiuna.

Como es sabido, el día 12 se estableció un gobierno de facto, el cual fue derrocado 48 horas después por otra insurrección civil y militar que repuso a Chávez en el poder. A las 3.30am del 14 de abril Chávez regresó al Palacio Presidencial en un final de película, con las multitudes que lo aguardaban y las cámaras que transmitían las imágenes al mundo. Pocos minutos después se dirigió a la nación, pidió perdón por sus errores y prometió rectificación y reconciliación. Si bien la confrontación política desarrollada en este episodio pareció resolverse a favor de las fuerzas del Gobierno, no fue un resultado político claro en lo inmediato. Esto condicionó la estrategia de los actores en pugna en los meses siguientes y desembocó en la segunda gran insurrección de las fuerzas de oposición: el paro petrolero.

El paro petrolero de diciembre de 2002 fue precedido por meses de tensa y continua conflictividad sociopolítica. Se inició con un paro cívico convocado por la $\mathrm{CD}$ el día 2 de diciembre, que a diferencia de la huelga general de abril, fue respaldado esta vez por la gerencia administrativa de PDVSA, buena parte de la gerencia operativa y por los capitanes de la Marina Mercante de la empresa que procedieron a paralizar las actividades diversas de esta industria. El lunes 9 de diciembre, día en que las fuerzas de la oposición convirtieron el paro en indefinido hasta que caiga Chávez, en cadena oficial trasmitida por todos los medios de comunicación audiovisual, el presidente de PDVSA, Alí Rodríguez Araque, reconoció que la compañía estaba ya virtualmente paralizada. En lo que sería un paso decisivo para conjurar la insurrección, Rodríguez Araque denunció el paro como un sabotaje criminal, convocando al pueblo a salir a la calle y rodear edificios, instalaciones y otros bienes de la empresa, a fin de apoyar al Gobierno en su esfuerzo por presionar a la gerencia a levantar la paralización. En las semanas siguientes, el pueblo, efectivamente, salió a la calle a rescatar la industria. El conflicto petrolero tomó protagonismo, perdiendo otras acciones y sectores su visibilidad $\mathrm{y} / \mathrm{o}$ centralidad.

Durante este paro indefinido, que se prolongó por más de dos meses, muchos comercios cerraron, supermercados y bancos trabajaron a medio turno, y los colegios privados y parte de los públicos paralizaron sus actividades. Los venezolanos, aunque no contaban con gasolina con que transportarse (ésta se fue agotando en diciembre), se mantenían en las calles con marchas y contramarchas que terminaban en violencia y aún muerte. La CD abolió las fiestas navideñas como símbolo del sacrificio necesario para alcanzar la victoria final, y las ciudades, especialmente Caracas, eran segregadas espacialmente entre territorios escuálidos (partidarios de la oposición) y chavistas (López Maya, 2003). Todas las noches había cacerolazos estruendosos en sectores de clase media y alta para exigir que Chávez renunciase. El 23 de enero de 2003, ya con claras señales de una derrota de la oposición, las fuerzas del Gobierno llamaron a una marcha que fue multitudinaria, mientras 
sectores de clases medias y altas se escondían tras las rejas de sus casas y practicaban planes de contingencia esperando, lo que líderes de la oposición llamaban el asalto de las hordas chavistas sobre las urbanizaciones de los sectores de mayores ingresos (García-Guadilla, 2003).

Pese a los muchos pronósticos que aseguraban que no había gobierno venezolano que aguantara un paro petrolero, el Gobierno lentamente retomó el control sobre la empresa estatal, reactivando las diferentes operaciones y profundizando el proceso de reestructuración de la misma, que había intentado con escaso éxito desde el inicio de su gestión. Por otra parte, durante el paro nunca se produjeron los estallidos sociales o las masacres previstas por las fuerzas de oposición, ni hubo desabastecimiento alimentario significativo. Hacia mediados de febrero, la tendencia de control del Gobierno sobre la industria se hizo clara y al finalizar el mes de marzo más de 18 mil gerentes y trabajadores de PDVSA habían sido despedidos por abandono del puesto de trabajo. La empresa había logrado rescatar todos sus tanqueros, se había iniciado el proceso de arranque de sus refinerías y las cifras de producción de barriles diarios se acercaban a la normalidad. Sin nunca ser decretado su final, el paro se fue disolviendo en febrero.

A diferencia del golpe de Estado, el paro petrolero produjo un resultado político más claro a favor del Gobierno y en consecuencia, la correlación de fuerzas cambió y, con ello, el escenario político general del país. Las fuerzas de la oposición, debilitadas, bajaron la movilización de calle y se volcaron a la estrategia de activar un referendo revocatorio presidencial, buscando con ello dejar a un lado el paro petrolero sin levantarlo explícitamente.

El referendo revocatorio que desarrolló en los meses siguientes la $\mathrm{CD}$, está contemplada como un derecho constitucional. El artículo 72 de la CRBV estipula su realización cumpliendo los siguientes requisitos: a) debe haberse cumplido la mitad del mandato de la autoridad; b) la solicitud debe estar respaldada como mínimo por un $20 \%$ de firmas de los electores inscritos en el Registro Electoral Permanente; c) cuando se haga el escrutinio, el número de electores que se pronuncian a favor de revocar el mandato debe ser superior al número de votantes que eligieron a la autoridad en cuestión; d) deben votar por lo menos el $25 \%$ de los electores inscritos en el REP; y e) sólo puede hacerse una vez. Poco antes de finalizar el año 2003, luego que pudo aprobarse la designación de las nuevas autoridades del Consejo Nacional Electoral (CNE), esta vía se despejó y el ente comicial autorizó y reguló los llamados para recoger las firmas del revocatorio presidencial, así como también las firmas de revocatorios para diputados de la AN, tanto oficialistas como de oposición. La recolección de las firmas tanto de las fuerzas del Gobierno como de la oposición tuvo lugar en dos semanas seguidas de noviembre y diciembre.

El 24 de febrero de 2004 se dio a conocer la primera decisión del CNE relativa a las firmas entregadas por la oposición. El CNE, en decisión dividida 3 a 2, puso bajo observación a más de 148.190 planillas entregadas (contentivas de aproximadamente 1.480.000 firmas), anunciando en los días inmediatos siguientes la aprobación del procedimiento para llevarlas a reparo (ratificación). Con esta decisión, el CNE posponía una convocatoria a revocatorio presidencial y lo condicionaba 
a una ratificación de firmas bajo observación para alcanzar el número necesario, pues las reconocidas como válidas eran insuficientes. Esto fue interpretado por algunos dirigentes y grupos de la CD como una trampa, que de hecho implicaba la suspensión del referendo presidencial.

A raíz de estas decisiones tomadas por el CNE, entre el 27 de febrero y el 4 de marzo de ese año, el país urbano, y sobre todo las zonas donde se residencian sectores sociales de ingresos medios y altos, sufrió una ola de protestas confrontacionales y violentas, desarrolladas a partir de llamados a la desobediencia civil por parte de voceros de la $\mathrm{CD}$, que rechazaron la decisión del CNE y expresaron desconocer la legitimidad del ente comicial (Aporrea, 2004). Las protestas, conocidas como el guarimbazo, incluyeron barricadas en autopistas y vías neurálgicas de Caracas y otras ciudades, quema de neumáticos, bolsas de basura y vehículos, balaceras en plaza Altamira, violencia física y verbal en diversos puntos urbanos, confinamiento de centenares de familias en sus hogares por los cierres de vía que impidieron llevar a los niños a las escuelas, acudir al trabajo, o llegar a centros de salud. El saldo trágico de este nuevo evento incluyó nueve muertos, decenas de heridos, unos cuarenta revoltosos con autos de detención, que en los días siguientes fueron liberados, y millones en pérdidas materiales (PROVEA, 2004). Ninguna organización política, ni la $\mathrm{CD}$, se responsabilizó por la violencia desatada, pero autoridades de municipios caraqueños controlados por la oposición se resistieron a reprimir tales protestas, argumentando que eran legítimas (López Maya, 2004).

Esta violencia acentuó las tensiones en el seno de la CD, entre quienes se pronunciaban por rechazar el proceso de reparo y retirarse de la vía del referendo, y quienes insistieron, pese a las dificultades, en proseguir por este camino. Esta última posición prevalecería luego de mucho debate. La oposición se avino a convocar a sus bases para reparar sus firmas, se realizó sin incidentes el acto de reparación, y el 3 de junio el CNE dictaminó que existían las firmas suficientes y se habían llenado los requisitos constitucionales para convocar al referendo revocatorio presidencial, que fijó para el 15 de agosto.

El 15 de agosto los electores venezolanos acudieron masiva y pacíficamente a las urnas. Las previsiones logísticas del CNE quedaron rebasadas por la importante afluencia de la participación ciudadana. El 16 de agosto en la madrugada, gracias al sistema computarizado de votación que se utilizó, el CNE pudo dar su primer informe oficial, totalizado con el $94,49 \%$ de las actas automatizadas y cuya tendencia consideró irreversible. La opción del NO, perteneciente al Presidente, había triunfado con una holgada mayoría: 4.991 .483 votos $(58,25 \%)$ contra la opción del SI, que en este primer boletín recibiría 3.576 .517 votos $(41,74 \%)$. Poco después, los observadores internacionales reconocidos por la oposición, el Centro Carter y la OEA, anunciaron la compatibilidad de sus cálculos con los resultados del CNE.

A partir de este hito el Gobierno se consolidó. La CD desapareció. En las elecciones regionales y municipales del 31 de octubre de 2004 el presidente Chávez y la alianza sociopolítica que lo sostenían avanzaron sobre las gobernaciones, triunfando en 20 de las 22 en disputa, ganando también la Alcaldía Mayor de Caracas y manteniendo el control sobre los dos municipios más poblados de la capital. 
La oposición ganó sólo en las gobernaciones del Estado Zulia y Nueva Esparta y disminuyó significativamente su control sobre alcaldías. La abstención se colocó en $54,3 \%$, habiendo sido en el referendo revocatorio de agosto de $30,1 \%$ (Lander y López Maya, 2005). Un año después, en las elecciones parlamentarias realizadas el 5 de diciembre de 2005, el oficialismo alcanzó una control del 100\% de los escaños en la AN, cuando las fuerzas de la oposición faltando escasos días para el acto de votación, decidieron retirarse de la contienda argumentando que las condiciones no garantizaban ni el voto secreto ni la transparencia de los resultados. El oficialismo se consolidó en el poder.

4. La gestión social y económica. Misiones, innovaciones participativas. Indicadores socioeconómicos ${ }^{4}$

Además de la confrontación política, fue aspecto destacado de la primera gestión los esfuerzos en lo social, expresados en las numerosas iniciativas para rescatar esta función del Estado e impulsar al mismo tiempo formas de participación de los individuos y las comunidades organizadas en la gestión de los servicios. El Gobierno impulsó desde 1999 diversas innovaciones participativas como las mesas técnicas dirigidas a crear espacios institucionales para la cogestión en el agua potable y servida, la energía, o el gas, o los comités de tierra urbanos o rurales, para apoyar el proceso de acceso a derechos de los pobres a la tenencia urbana y rural. También impulsó formas de economía social como las cooperativas y los núcleos de desarrollo endógeno (NUDES), dentro de su propósito de transitar hacia un régimen de democratización de los medios de producción.

Los resultados fueron positivos en algunos casos. A modo de ejemplo y sin pretensión de ser exhaustivos, a continuación señalamos algunas iniciativas relevantes de la gestión social de estos años.

Simoncitos, escuelas y liceos bolivarianos. Desde 1999 el Gobierno buscó ampliar la matrícula del preescolar y recuperar la educación primaria y secundaria pública, severamente reducida por el achicamiento del Estado y del gasto fiscal en los años precedentes. Se recuperó la jornada completa, se garantizaron uniformes, útiles, comidas y meriendas gratuitas, y se debilitaron las prácticas veladas de pagos de matrícula que se venían exigiendo. Según cifras oficiales, en este período se constituyeron 5.654 escuelas bolivarianas, que cubrieron una población estudiantil que superó el millón. La educación pasó a percibir alrededor del 8\% del PIB, superando las recomendaciones de la UNESCO.

Las misiones. En 2003 comenzaron a operar las "misiones", inicialmente concebidas como operativos de emergencia para solucionar las carencias históricas y/o generadas por el paro petrolero en las condiciones de vida de amplios sectores pobres. ${ }^{5}$ Las misiones tuvieron también desde sus inicios implícitos propósitos electorales, primero con vista al referendo revocatorio de 2004 y posteriormente a otros comicios, como la reelección presidencial de 2006 y el referendo sobre la propuesta de reforma constitucional de 2007. Las misiones han promovido estructuras de la administración pública paralelas a las tradicionales, y comportan como requisito la organización y participación de las comunidades en la gestión 
misma del servicio, accediendo éstas por esta vía a un derecho social negado en el pasado. En muchas misiones participa la Fuerza Armada, considerada una de las pocas estructuras del Estado que funciona y es leal al bolivarianismo, dentro de la concepción de la alianza militar-civil. Las primeras misiones se hicieron bajo la asesoría del gobierno de Cuba, que a partir de 2002 se vuelve un socio central del gobierno bolivariano. Las primeras serían Misión Robinson I y II, dirigidas a superar el analfabetismo y permitirle a la población adulta culminar la educación básica; Misión Barrio Adentro I, para garantizar el derecho de los pobres a la salud mediante la colocación en los barrios populares de servicios de atención preventiva y primaria, principalmente con médicos cubanos; y Misión Mercal, para distribuir y comercializar alimentos en los sectores populares, que con el tiempo ha resultado en una distribuidora estatal de alimentos que satisface esta demanda -según el Gobierno- a aproximadamente la mitad de la población a precios subsidiados. En la medida en que los ingresos fiscales se multiplicaban por el auge de los precios internacionales del barril petrolero, se fueron ampliando estas misiones, llegando a sobrepasar las veinte hacia el final del primer gobierno de Chávez. Destacan entre otras: Misión Identidad, para garantizar un documento de identidad a todos los venezolanos; Misión Guaicaipuro, para el acceso de los indígenas a sus derechos; Misión Cristo, para corregir la pobreza extrema; Misión Barrio Adentro 2 y 3; Misión Milagro, para servicios oftalmológicos; Misión Sucre y Ribas, para el acceso a educación secundaria y universitaria, todas ellas financiadas con los ingresos extraordinarios de la renta petrolera.

Cooperativas, fundos zamoranos y NUDES. Como pilares de la economía social y clave de la "participación y el protagonismo del pueblo" según la CRBV (Artículo 70) se dio amplio apoyo a las cooperativas. Existieron en Venezuela mucho antes, pero crecieron exponencialmente estos años (ver PROVEA, informes anuales). Sin desmerecer lo positivo de la iniciativa, este crecimiento vertiginoso incentivado por los considerables aportes financieros disponibles acarreó muchos problemas para cumplir el objetivo social propuesto por esta forma organizativa, y el mismo Gobierno reconoció a fines de este periodo que la mayoría de las cooperativas fundadas no cumplían sus propósitos. Los fundos zamoranos (convertidas luego en Misión Vuelvan Caras y después en Misión Che Guevara) y los núcleos de desarrollo endógeno (NUDES), fueron otras iniciativas que combinaban la concepción comunitaria participativa con la búsqueda de democratización de los medios de producción. Al igual que las misiones, fueron pensadas más como mecanismos de emergencia para afrontar los graves problemas de desempleo y falta de preparación de la mano de obra venezolana que como nuevas formas de una economía productiva. La idoneidad o viabilidad económica de las mismas ha jugado un rol secundario y por ello sus logros económicos son escasos.

Como resultado de la bonanza de ingresos fiscales y de estas iniciativas de gestión en lo social, desde 2004 y hasta fines de este período, Venezuela experimentó una recuperación económica y social que va a contribuir de manera clave en la impresionante victoria del presidente Chávez en las elecciones presidenciales de 2006 (véase Cuadros $\mathrm{N}^{\circ} 1$ y N²). 


\section{Cuadro $\mathrm{N}^{0} 1$}

Algunos indicadores macroeconómicos 2003 - 2006

\begin{tabular}{|c|c|c|c|c|c|}
\hline Año & $\begin{array}{c}\text { Precio } \\
\text { barril cesta } \\
\text { venezolana } \\
\text { (US\$) }\end{array}$ & $\begin{array}{c}\text { Reservas } \\
\text { Internacionales } \\
\text { (millones de } \\
\text { US\$) }\end{array}$ & $\begin{array}{c}\text { Inflación } \\
\text { (\% Vr IPC) }\end{array}$ & $\begin{array}{c}\text { Variación } \\
\text { del PIB }\end{array}$ & $\begin{array}{c}\text { Tipo de } \\
\text { Cambio } \\
\text { (Bs. x \$) }\end{array}$ \\
\hline 2003 & 25,8 & 21.366 & 27,1 & $-7,7$ & 1600 \\
\hline 2004 & 33,4 & 24.208 & 19,2 & 17,9 & 1920 \\
\hline 2005 & 45,5 & 30.368 & 14,4 & 9,3 & 2150 \\
\hline 2006 & 55,9 & $31.917^{*}$ & $13,4 * *$ & $9,6 * *$ & 2150 \\
\hline
\end{tabular}

* Primer semestre

** Acumulado hasta el mes de octubre

Fuente: Banco Central de Venezuela (2006) y Ministerio de Energía y Petróleo.

\section{Cuadro $\mathbf{N}^{0} 2$}

Algunos indicadores socioeconómicos 2003 -2006

\begin{tabular}{|c|c|c|c|c|}
\hline Año & $\begin{array}{c}\text { Tasa de } \\
\text { desocupación } \\
\mathbf{( \% )}\end{array}$ & $\begin{array}{c}\text { Hogares en } \\
\text { pobreza } \\
(\%)\end{array}$ & $\begin{array}{c}\text { Hogares } \\
\text { en pobreza } \\
\text { extrema } \\
(\%)\end{array}$ & $\begin{array}{c}\text { Índice de } \\
\text { Desarrollo } \\
\text { Humano }\end{array}$ \\
\hline 2003 & 16,8 & 55,1 & 25,0 & 0,76 \\
\hline 2004 & 13,9 & 47,0 & 18,5 & 0,80 \\
\hline 2005 & 13,0 & 37,9 & 15,3 & 0,81 \\
\hline 2006 & $9,9 *$ & $33,9 * *$ & $10,6^{* *}$ & -- \\
\hline
\end{tabular}

* Tercer trimestre

** Primer semestre

Fuente: Instituto Nacional de Estadística INE (2006).

\section{Las elecciones de 2006: hacia el socialismo del siglo XXI}

Triunfante en el referendo revocatorio de 2004, el presidente Chávez anunció su intención de reorientar el proceso de cambios hacia un Socialismo del siglo XXI. Este fue un concepto que anunció en 2005 en el Foro Social Mundial de Porto Alegre y lo asoció inicialmente con ideas abstractas de solidaridad y libertad. Sostuvo el Presidente entonces, que dicho socialismo debía construirse como algo nuevo, apartándose de experiencias previas como el modelo soviético y cubano. El tema se incorporó a la polarización política de la campaña presidencial de 2006, tildando Chávez de burgueses y capitalistas a los adversarios a su propuesta. El carácter 
vago de este socialismo le permitió constituirse durante la campaña por la Presidencia en un concepto vacío -como este término es definido por Laclau (2005)donde cada quién depositó aspiraciones o temores. Aparte de algunas propuestas puntuales de modificaciones al sistema político, como la reelección indefinida del Presidente, la creación de un nuevo Poder Popular basado en la experiencia del parlamentarismo de calle $e^{6}$ la eliminación del principio de la representación proporcional en los cuerpos deliberantes, poco más se supo de ese modelo de sociedad hasta 2007, una vez que Chávez triunfó en la contienda presidencial y se aseguró un nuevo mandato de seis años.

La victoria del presidente Chávez en los comicios de diciembre de 2006 fue contundente. Recibió el voto de más de siete millones de venezolanos, el $63 \%$ de los votos válidos (CNE, 2007). Fue una victoria sin precedentes. A partir de allí se abrió otra etapa de gestión gubernamental.

\section{La segunda gestión de Chávez (2007 a hoy): el socialismo del siglo XXI}

Una vez alcanzada la victoria electoral, el Presidente comenzó a verter contenidos concretos a su propuesta socialista. En discursos clave que dio en las semanas siguientes a su triunfo precisó ideas, estrategias e instrumentos para provocar lo que llamó la transformación revolucionaria de la sociedad (Chávez, 2006 y 2007). En estos textos, se da un giro más estatista a las orientaciones económicas del Gobierno y se expresan más claramente tendencias a socavar las instituciones liberales que se habían aprobado en la Constitución de 1999. La dimensión participativa de la CRBV tiende a restringirse para localizarse principalmente en formas de gestión popular de políticas públicas en el nivel micro a través de la modalidad de los consejos comunales (CC), articulados y dependientes del gobierno central. En la dimensión política del socialismo, el Presidente llamó a crear el Partido Socialista Unido de Venezuela (PSUV), demandó la disolución de todos los partidos de la alianza, incluido el suyo propio, el partido MVR, y advirtió a quienes no atendieran a su llamado, que deberían irse de su gobierno.

\section{La fallida reforma constitucional de 20077}

Con la finalidad de acelerar los cambios conducentes al socialismo, el Presidente anunció en enero de 2007 el impulso a cinco motores constituyentes. El primer motor sería una Ley Habilitante, que permitiría a la AN delegar en el Ejecutivo por un período delimitado la capacidad de elaborar leyes (CRBV, Artículo 203). Chávez la consideró la "ley de leyes revolucionaria, madre de leyes". El segundo, una "integral y profunda" reforma de la CRBV, con el cual el Presidente podría, entre otros aspectos, modificar artículos que en lo económico o en lo político obstruyeran el camino hacia el socialismo. El tercer motor lo llamó "jornada de moral y luces", y comprendía una campaña de educación en todos los espacios de la sociedad. Chávez denominó el cuarto motor "la geometría del poder", donde propondría una nueva manera de distribuir los poderes político, económico, social y militar sobre el espacio nacional, para generar sistemas de ciudades y territorios federales más cónsonos, según él, con su modelo de socialismo. Chávez planteó 
como un quinto motor -y el más importante- la "explosión revolucionaria del poder comunal", según la cual se conformaría en el Estado un Poder Popular que cambiaría la naturaleza de éste y lo haría socialista. Consideró que todos estos motores estaban interconectados entre sí, y que la explosión creadora del Poder Comunal dependería para su desarrollo, expansión y éxito, de todos los anteriores (MINCI, 2007). ${ }^{8}$

Poco después, el Ejecutivo introdujo a la AN el proyecto de Ley Habilitante solicitando la facultad de elaborar leyes en diez ámbitos de la administración pública durante año y medio, el que dos semanas después sería aprobado por unanimidad, incorporando la AN un ámbito adicional, el de hidrocarburos. El 15 de agosto de ese año el Presidente entregó su propuesta de reforma constitucional.

El proyecto de reforma que presentó Chávez constó de 33 artículos, que la AN amplió a 69 en el breve tiempo de dos meses en que lo discutió. Entre los cambios relevantes que esta propuesta tuvo destacaron: la reelección indefinida para el Presidente y un aumento del período presidencial de seis a siete años (Artículo 230); la potestad del Presidente para crear regiones especiales con fines estratégicos y nombrar autoridades especiales con el fin de garantizar la soberanía y defensa del territorio en situaciones de contingencia o desastres (Artículo 11); la ciudad como unidad político primaria de organización territorial en vez del municipio (Artículo 16); la reducción de la jornada laboral a seis horas diarias y treinta y seis semanales (Artículo 90); la creación de un fondo de seguridad social para trabajadores por cuenta propia (Artículo 87); la institucionalización de las misiones como una segunda administración pública paralela a la tradicional (Artículo 141). El proyecto propuso elevar todos los porcentajes de firmas necesarios para activar los distintos mecanismos de participación popular (Artículos 72, 74 y 348) con lo cual los tornó prácticamente inviables; la creación del Poder Popular como una nueva forma del poder público, conformado a partir de las "comunidades" (núcleo espacial del Estado Socialista) (Artículo 16). Este Poder no sería representativo: "no nace del sufragio ni de elección alguna, sino de la condición de los grupos humanos organizados como base de la población" (Artículo 136).

Otras propuestas serían las dirigidas a una recentralización del aparato estatal como la potestad del Presidente para nombrar los vicepresidentes que estimara necesarios (Artículo 125) y la sustitución del Consejo Federal de Gobierno por un Consejo Nacional de Gobierno. La propuesta también contemplaba la eliminación de la autonomía del Banco Central de Venezuela; la denominación sin clara conceptualización de cinco tipos de propiedad: social directa e indirecta, pública, mixta, privada y colectiva; la eliminación del texto constitucional que indica que el Estado garantiza el "derecho" a la propiedad, el que fue reemplazado por "reconoce" tal derecho. En lo militar se propusieron varias reformas: incorporación de un nuevo componente de la Fuerza Armada, la Milicia Nacional Bolivariana; cambio del nombre de la Fuerza Armada Nacional por Fuerza Armada Bolivariana y otorgamiento a los militares de actividades de seguridad interna (Artículo 329).

El 2 de diciembre se celebró el referendo para la aprobación de la propuesta de reforma, la cual fue rechazada por los electores. De acuerdo con el último boletín 
emitido por el CNE, con el escrutinio de 94\% de las actas, el resultado arrojó 4.521.494 votos contrarios a la aprobación de la reforma y 4.404.626 favorables ${ }^{9}$, lo que significa una estrecha diferencia de 116.868 votos, es decir, de apenas el $1,3 \%$ de los votos válidos. Fue éste el último boletín emitido por el CNE, cuando todavía faltaban por contabilizar unas 2.000 actas, correspondiendo aproximadamente la mitad de ellas a mesas manuales. Aunque no hay resultados definitivos, puede estimarse que la abstención fue ligeramente superior del $40 \%$ del registro electoral (CNE, 2008).

Pese a este rechazo por parte del electorado, en la práctica de los meses y años siguientes muchas de las propuestas rechazadas se han venido consagrando a través de reformas a diversas leyes ordinarias y orgánicas, usando el Presidente el recurso constitucional de la Ley Habilitante o por la aprobación de reformas a leyes por parte de la AN, que Chávez controla holgadamente. Las Líneas Generales del Desarrollo Económico y Social de la Nación 2007-2013 (en adelante LGDESN 2007-2013), elaboradas simultánea y coordinadamente con la reforma constitucional fallida, no han sufrido modificaciones, manteniéndose como el plan estratégico que orienta en este período el proceso de transformaciones hacia el socialismo.

\section{Las Líneas Generales del Desarrollo Económico y Social de la Nación 2007-2013 10}

Según las LGDESN 2007-2013 -cuya introducción lleva como novedad la utilización del título comandante presidente en la firma de Hugo Chávez- el modelo socialista propuesto por el Gobierno tiene como directrices: a) la creación de una Nueva Ética Socialista sostenida sobre las corrientes humanistas del socialismo y las nacionalistas de Simón Bolívar; b) la búsqueda de la Suprema Felicidad Social a partir de la construcción de una sociedad incluyente; c) la construcción de una Democracia Protagónica y Revolucionaria, entendida como una que transforma la debilidad del individuo en fuerza colectiva y; d) un Modelo Productivo Socialista, concebido como la supresión de la división y jerarquización social del trabajo y la eliminación del criterio de la producción de riqueza subordinada a la reproducción del capital, para ser sustituida por otro que sirva a la satisfacción de las necesidades humanas. Adicionalmente, este documento señala una modificación de la estructura socio territorial para ajustarla al nuevo modelo productivo, la utilización del petróleo para convertir a Venezuela en una Potencia Energética Mundial, y la promoción de una Nueva Geopolítica Internacional dirigida a la búsqueda de la multipolaridad como orden internacional (LGDESN 2007-20013: 5-6).

Según la directriz de la ética socialista, el primer desafío planteado en esta gestión es superar la miseria y la pobreza material y espiritual mediante la construcción de un Estado ético con funcionarios que exhiban una conducta moral en sus condiciones de vida. El documento, evidenciando influencias del pensamiento rousseauniano, afirma que hay valores, principios, que están en la conciencia social "no por un pacto sino por algo que está dentro de cada uno y del corazón social, que lo sentimos como un deber de la humanidad (...)" (p. 9). La nueva 
ética llevará al "hombre nuevo", con el cual se superará la "prehistoria humana" y entraremos a la "verdadera historia", la del socialismo (p. 10).

Según la directriz de la suprema felicidad social, la nueva estructura social incluyente estará basada en formas de propiedad social conteniendo en esta acepción las autogestionada, asociativa y comunitaria (p.12). Las LGDESN 2007-2013 sólo enuncian estos tres tipos de propiedad sin darles definición alguna. En la rechazada propuesta de reforma constitucional de 2007, la propiedad social había sido definida como "aquella que pertenece al pueblo en su conjunto y las futuras generaciones, y podrá ser de dos tipos: la propiedad social indirecta cuando es ejercida por el Estado a nombre de la comunidad, y la propiedad social directa, cuando el Estado la asigna bajo distintas formas y en ámbitos territoriales demarcados a una o varias comunidades, a una o varias comunas, constituyéndose así en propiedad comunal o a una o varias ciudades, constituyéndose así en propiedad ciudadana" (itálicas nuestras). ${ }^{11}$

En las LGDESN 2007-2013 se contemplan además de las anteriores la propiedad pública y la "individual", sin definir esta segunda, que parece reemplazar a la propiedad privada con lo cual ésta se debilita. Con respecto a la propiedad pública fue definida en la rechazada reforma de 2007 como perteneciente "a los entes del Estado", configurando una propiedad distinta a la social indirecta y sin aclarar por qué. En correspondencia con estos lineamientos, el Gobierno ha venido estatizando industrias de distinto tipo. En algunos casos se trata de re-estatizaciones, pues fue durante el período de hegemonía neoliberal que fueron privatizadas. Entre éstas se encuentran la Siderúrgica del Orinoco (Sidor) y la Compañía Anónima Nacional de Teléfonos de Venezuela (CANTV). Otras nunca habían sido empresas públicas como La Electricidad de Caracas y Cementos Mexicanos. Cabe señalar que estas estatizaciones se hicieron con el debido pago de indemnizaciones.

La transformación de la estructura social se hará posible, según el documento, por "la nueva forma de utilizar la renta petrolera" a través de su inversión en políticas sociales masivas y aceleradas como las misiones, que permiten universalizar la satisfacción de necesidades básicas como alimentos, salud, educación, vivienda, empleo e identidad (LGDESN, 2007: 12). Otros objetivos específicos de esta directriz son reducir a cero la miseria para el período hasta 2013, fortalecer la accesibilidad de los alimentos, apoyar la organización y participación de los trabajadores en la gestión de las empresas e incrementar la participación de los CC en la planificación y control de la economía, así como establecer mecanismos para la socialización de los excedentes (pp. 14-16).

A diferencia de lo consagrado en la CRBV, que preservando formas institucionales de democracia representativa integra adicionalmente formas directas de participación, en las LGDESN 2007-2013 se incorpora la directriz de la Democracia Protagónica Revolucionaria, que se define como alternativa a la democracia representativa clásica y aparentemente es distinta también a la participativa y protagónica: "Dado que la soberanía reside en el pueblo, este puede por si mismo dirigir el Estado, sin necesidad de delegar su soberanía, tal como en la práctica sucede con la democracia representativa o indirecta" (itálicas nuestras, p.17). 
En la misma directriz se apunta hacia el debilitamiento de la noción del Estado de derecho: "En la democracia protagónica revolucionaria ... la justicia está por encima del derecho; y las condiciones para garantizar el bienestar de todos, tales como educación, salud y trabajo están por encima de la simple formalidad de la igualdad ante la ley y el despotismo mercantil" (itálicas nuestras, p. 18).

En la directriz sobre el modelo productivo socialista se establecen las llamadas empresas de producción social (EPS), consideradas el germen del socialismo del siglo XXI. Se definen como empresas que se dedican a producir bienes y servicios sin los valores capitalistas del egoísmo y la ganancia. En ellas no existen privilegios y hay igualdad sustantiva entre sus integrantes, usan la planificación participativa y protagónica, y el excedente se reparte en proporción al trabajo aportado (p. 25). Estarán apoyadas por la industria petrolera y empresas del Estado productoras de bienes básicos, que delegarán en ellas progresivamente actividades productivas. Asimismo, empresas del Estado, de acuerdo a sus particularidades, se irán transformando en EPS (p. 25).

El modelo productivo socialista busca consolidar una economía endógena de múltiples encadenamientos productivos internos, diversificando el potencial exportador de bienes y servicios después que se hayan satisfecho las necesidades internas. Propiciará una política comercial cónsona con el desarrollo endógeno y una innovación científica y tecnológica adaptada al objetivo de satisfacer las necesidades humanas. Además de la industria básica energética, se dará prioridad a la producción de alimentos, manufacturas y servicios básicos para la población ( $\mathrm{p}$. 26 y 27). Este documento oficial enfatiza la actividad de producción de alimentos dentro de la llamada política de seguridad alimentaria, entendiendo por ello un desarrollo rural integral por considerar que permitiría una reocupación más equilibrada del territorio, la redistribución del ingreso y aportaría las materias primas a la industria. Por tanto se asienta que se busca culminar una revolución agraria -no una reforma agraria- (p. 27). Entre otros de los múltiples objetivos del nuevo modelo de economía, se señala explícitamente el apoyo a la pequeña y mediana industria así como a las cooperativas (p. 30).

Las LGDESN 2007-2013 buscan también una reocupación del espacio en Venezuela bajo la idea de un Desarrollo Territorial Desconcentrado, resultado de una planificación integral, que articule la construcción y organización del nuevo modelo productivo endógeno donde emergerán las nuevas relaciones sociales ( $\mathrm{p}$. 33). Implica esta directriz un cambio de rumbo con relación a las tendencias de descentralización político administrativas de las décadas finales del siglo XX, que quedaron expresadas en la Constitución de 1999, quedando ahora ausentes en este documento los poderes regionales y municipales. Finalmente, contemplan otras dos directrices: Venezuela Potencia Energética Mundial y Nueva Geopolítica Internacional, donde se reitera el papel clave de la industria petrolera como "corresponsable de primera línea" del nuevo modelo productivo (p. 42), y se hace énfasis en la utilización de los recursos energéticos para la integración latinoamericana y caribeña, y para el fortalecimiento de polos de poder mundial alternativos al imperialismo norteamericano. 


\section{Las elecciones regionales y locales de 2008}

En las elecciones del 28 de noviembre se eligieron 22 de los 23 gobernadores de las entidades federales venezolanas, 325 alcaldes, 233 diputados de las asambleas legislativas de los estados, el alcalde mayor de Caracas y los 13 concejales de la Alcaldía Metropolitana. Los resultados arrojaron un triunfo del oficialismo en diecisiete de estas gobernaciones, con el 52,7\% de los votos. En términos absolutos el oficialismo aumentó su caudal electoral en algo más de 1.137 .320 votos con relación a los votos obtenidos en 2007, cuando perdió el referendo constitucional con un total de 4.404.626 votos (López Maya, 2008). Con relación a las alcaldías, se adjudicaron 265 de un total de 337 en disputa, con lo cual superaron el número de alcaldías que ganaron en 2004 que fueron 226 (CNE, 2008). ${ }^{12}$

Las fuerzas opositoras por su parte, conservaron las dos gobernaciones ganadas en las elecciones anteriores (2005) y agregaron tres más, volviendo al número de gobernaciones que habían obtenido en 2000 y concentrando 41,7\% de los votos. En términos absolutos, la sumatoria de los votos de candidatos a gobernadores alcanzó un total de 4.225.103 votos, lo que significó una merma en términos absolutos de 296.391 votos con relación a los votos obtenidos en el referendo de reforma constitucional de 2007 cuando alcanzaron los 4.521 .494 votos.

La oposición triunfó en cuatro de las cinco alcaldías de la Zona Metropolitana de Caracas, ganando así mismo la Alcaldía Mayor. Su desempeño a nivel local aparte de Caracas fue pobre, pues sólo obtuvieron predominio en 53 alcaldías de las 337 en disputa. Otras 19 quedaron bajo control de fuerzas disidentes del oficialismo (8), independientes (2), sin información (9). Estos datos revelan que si bien algunos candidatos a gobernadores de la oposición se posicionaron en espacios regionales importantes, y Caracas favoreció candidatos opositores, el oficialismo salió mucho más fortalecido en esta contienda que la oposición, tanto porque creció en términos absolutos, como porque ahora controla casi el $80 \%$ de los alcaldes (López Maya, 2008). Es de señalar, que en todos los estados, incluso los que tienen gobernadores de oposición, la mayoría de los alcaldes son del oficialismo.

El Presidente, estimulado por esos favorables resultados, consideró que se había recuperado de la derrota sufrida en el referendo constitucional del año anterior y que el momento político era propicio para insistir en un tema ya derrotado en la propuesta de reforma constitucional: su reelección indefinida.

\section{15 de febrero de 2009: referendo de enmienda constitucional ${ }^{13}$}

Escasos días después de las elecciones regionales y locales, y en clara respuesta a los resultados obtenidos en ellas, el presidente Chávez comenzó a proponer públicamente la idea de activar un referendo para hacer aprobar una enmienda constitucional. La AN ampliamente controlada por Chávez aprobó ya el 19 de diciembre, en primera discusión, una propuesta de redacción. Esa propuesta inicial estaba limitada al cambio de un único artículo, el 230, para eliminar las limitaciones a la reelección del Presidente. El 5 de enero, el Presidente, persuadido de la necesidad de sumar los votos de la mayor parte de la disidencia chavista, aceptó la idea del partido PPT de ampliar su propuesta para modificar cuatro artículos 
más de la constitución y permitir la reelección indefinida de todos los cargos de elección popular. Había sido hasta entonces feroz opositor de la idea pero necesitaba los votos. Así mismo presionaba al CNE para que el referendo fuese lo más pronto posible.

El 14 de enero la AN aprobó la convocatoria de un referendo para enmendar cinco artículos de la CRBV. El CNE convocó el referendo para el 15 de febrero. La pregunta que fue sometida a consulta decía así: “¿Aprueba usted la enmienda de los artículos 160, 162, 174, 192 y 230 de la Constitución de la República tramitada por la Asamblea Nacional que amplía los derechos políticos del pueblo con el fin de permitir que cualquier ciudadano o ciudadana, en ejercicio de un cargo de elección popular, pueda ser sujeto de postulación como candidato o candidata para el mismo cargo por el tiempo establecido constitucionalmente dependiendo su posible elección exclusivamente del voto popular?". Para garantizar transparencia y equidad una pregunta sometida a referendo debe ser neutral y no inducir al elector por alguna de las opciones, ésta claramente no lo era.

El triunfo de la propuesta de Chávez fue en términos absolutos y porcentuales bastante claro: con el $54,85 \%$ de los votos válidos, el SI a favor de la enmienda se colocó casi $10 \%$ sobre el NO, alcanzando 6.310 .482 votos. El NO por su parte obtuvo 5.193.839 de votos, el 45,14\% (CNE, 2009).

Durante el período de campaña fue notoria la desigualdad de la competencia electoral a favor de la propuesta del Presidente. Se presenció de manera descarnada la utilización de los recursos públicos por parte de su parcialidad política, incluyendo el uso de los organismos del Estado. El 7 de enero desde un acto del Comando Simón Bolívar transmitido por cadena nacional de radio y televisión, la ministra del Poder Popular para el Desarrollo Social exhortó a instancias participativas como las mesas técnicas y los CC a abandonar las obras y dedicarse, de lleno, a buscar los votos para que se impusiese la propuesta del Presidente de permitir la reelección en todos los cargos. ${ }^{14}$ El 15 de febrero, durante la jornada electoral, militantes y simpatizantes del Presidente se presentaron a los centros de votación con propaganda proselitista a favor de la opción del SI. Igualmente se observó el uso de comedores de distintos entes públicos dedicados a proporcionar almuerzos para los militantes de la parcialidad política del Presidente que conformaban las mesas electorales. ${ }^{15}$

En su informe sobre el referendo del 15 de febrero, Ojo Electoral, asociación independiente de observación electoral nacional, registró múltiples y variadas violaciones de las regulaciones emitidas por el CNE. Destacan, la abusiva participación de diferentes organismos públicos en la promoción de la opción impulsada por el Presidente: contabilizó que el $16 \%$ de toda la propaganda fue pautada por dichos organismos; calculando los costos en publicidad en medios impresos, según sus tarifas comerciales, Ojo Electoral determinó que el $71 \%$ de la publicidad fue pautada por el bloque del SI, el $15 \%$ por organismos públicos con publicidad indirecta favorable al SI y sólo el 14\% por el bloque del NO (Ojo Electoral, 2009). 
4. Desempeño socioeconómico: auge y crisis de los precios petroleros y sus consecuencias

Habíamos señalado ya en la primera gestión, que desde 2004, cuando se superaron los más agudos conflictos políticos, comenzaron a registrarse en el país indicadores macroeconómicos de sostenida mejoría. Este comportamiento de la economía fue similar al resto de América latina, si bien los promedios venezolanos fueron superiores a los de la región. El auge de los precios de materias primas en el mercado internacional y particularmente el auge de los precios petroleros, son parte principal de la explicación de este positivo y sostenido desempeño macroeconómico venezolano. ${ }^{16}$ También contribuyen a explicar-vía el aumento del ingreso fiscal petrolero- la sostenida popularidad del Presidente y sus proyectos políticos. La situación se prolongó hasta 2008 (ver López Maya y Lander, 2009). Sin embargo, desde 2007, y pese a un notable crecimiento del PIB todavía ese año, comenzó una desaceleración con relación a los años anteriores, que se hizo franco decrecimiento del PIB en 2009 (ver Cuadro No 3) y continuó en 2010. Este desempeño del PIB revela que, pese al discurso que enfatiza un tránsito acelerado al socialismo, la economía mantiene las mismas características rentistas del pasado, pues sigue manifestando una alta dependencia de los vaivenes del precio petrolero en el mercado mundial, siendo fundamentamente dinamizada por el gasto público estrechamente condicionado por el ingreso fiscal petrolero. ${ }^{17}$

\section{Cuadro $N^{\circ} 3$}

\section{Algunos Indicadores del desempeño de la economía y la sociedad ve- nezolana (2007-2009)}

\begin{tabular}{|c|c|c|c|c|c|c|c|}
\hline AÑO & $\begin{array}{c}\text { Precio } \\
\text { cesta } \\
\text { petrolera } \\
\$\end{array}$ & $\begin{array}{c}\text { Variación } \\
\text { PIB }\end{array}$ & Inflación & $\begin{array}{c}\text { Tasa } \\
\text { Desocu- } \\
\text { pación }\end{array}$ & $\begin{array}{c}\text { Hogares } \\
\text { Pobreza }\end{array}$ & $\begin{array}{c}\text { Hogares } \\
\text { Extrema } \\
\text { Pobreza }\end{array}$ & GINI \\
\hline 2007 & 65,13 & 8,2 & 22,5 & 8,5 & 28,5 & 7,9 & 0,427 \\
\hline 2008 & 89,08 & 4,8 & 30,9 & 7,4 & 27,5 & 7,6 & 0,41 \\
\hline 2009 & 56,93 & $-3,3$ & 25,1 & 7,9 & 24,2 & 6,6 & 0,39 \\
\hline
\end{tabular}

Fuentes: INE, BCV, CEPAL, base de datos de Luis E. Lander.

El Cuadro $\mathrm{N}^{\circ} 3$ revela el comportamiento de la inflación, que durante los años de bonanza petrolera se mantuvo siempre muy alta, continuando hasta 2009, cuando ya el PIB es negativo. Es una inflación con índices de dos dígitos, superiores al promedio de América latina y por lo general también por encima de los estimados por el propio Gobierno. Especialmente relevante es el hecho de que la inflación en alimentos y bebidas no alcohólicas, que es el que más afecta a los sectores pobres de la población, ha sido siempre superior al índice general. Esto, aunque repercute 
en las condiciones de vida de las mayorías, parece hasta la fecha no reflejarse en indicadores sociales clave. Según datos oficiales desde 2004 y hasta 2008, se observa una continua mejoría de las tasas de desocupación y los indicadores de pobreza y pobreza extrema (ver Cuadro $\mathrm{N}^{\circ} 3$ ). En 2009, sin embargo, ya hubo un aumento de $0,5 \%$ de la tasa de desocupación.

Como se señaló, según las LGDESN 2007-2013, el modelo socialista que se busca implantar pasa en primera instancia por la conformación de un mercado interno vigoroso que satisfaga las necesidades más elementales de la población: alimentos, vivienda, salud y educación. El fortalecimiento del mercado interno puede observarse en el Cuadro $\mathrm{N}^{\circ} 4$, que ilustra cómo ha venido creciendo el comercio en general, con particular fuerza al por menor. Así mismo se ha incrementado el gasto final de los hogares venezolanos, que registró desde 2004 un crecimiento de $74 \%$ (BCV, 2009).

Cuadro $\mathrm{N}^{\circ} 4$

Variación del índice de volumen de ventas 2004-2008

\begin{tabular}{|c|c|c|c|}
\hline Año & General \% & $\begin{array}{c}\text { Comercio al por } \\
\text { mayor \% }\end{array}$ & $\begin{array}{c}\text { Comercio al por } \\
\text { menor \% }\end{array}$ \\
\hline 2004 & 27,11 & 21,95 & 28,37 \\
\hline 2005 & 29,39 & 19,30 & 33,04 \\
\hline 2006 & 34,10 & 39,16 & 31,77 \\
\hline 2007 & 34,69 & 18,63 & 42,49 \\
\hline 2008 & 10,51 & 1,98 & 13,95 \\
\hline
\end{tabular}

Fuente: BCV, 2009.

\section{Cuadro $\mathrm{N}^{\circ} 5$}

Distribución de alimentos en Mercal

\begin{tabular}{|c|c|c|c|}
\hline Año & $\begin{array}{c}\text { Total en ton } \\
\text { métricas }\end{array}$ & Nacional \% & Internacional \% \\
\hline 2003 & 382.860 & 14 & 86 \\
\hline 2004 & 1.122 .517 & 50 & 50 \\
\hline 2005 & 1.397 .579 & 64 & 36 \\
\hline 2006 & 1.383 .269 & 66 & 34 \\
\hline 2007 & 1.408 .490 & 47 & 53 \\
\hline $2008^{*}$ & 1.492 .263 & --- & --- \\
\hline
\end{tabular}

Fuente: Anuario Provea 2008 y * Memoria y Cuenta MINPPAL 2008. 
Mercal ha sido una de las misiones de mayor impacto en el logro de este objetivo. Esta misión distribuye alimentos a precios subsidiados y está dirigida a satisfacer la necesidad básica de alimentación dentro de la política de seguridad alimentaria. El Cuadro $\mathrm{N}^{\circ} 5$ muestra su sostenida expansión en el mercado de consumo alimentario del país. Es una manifestación más de la nueva orientación en el uso de la renta petrolera. También se observa que el componente importado del total de toneladas distribuidas es siempre muy superior al componente nacional, volviendo a revelar el carácter rentista de la economía petrolera y su dependencia del ingreso fiscal.

Otro indicador que permite evaluar la fragilidad de este modelo económico es el concerniente a los esfuerzos hasta ahora realizados para acometer la llamada revolución agraria.

Tanto en la CRBV como en las LGDESN 2001-2007, la agricultura fue considerada estratégica en el proceso de transformaciones profundas perseguidas. Se planteó combatir el latifundio y buscar un desarrollo rural integral a través del estímulo al empleo en el campo y el bienestar de la población rural a través de la dotación de obras de infraestructura, insumos, créditos, servicios de capacitación y asistencia técnica. Así mismo, desde el inicio se buscó fomentar cooperativas y asociaciones diversas de microempresas y formas asociativas bajo régimen de propiedad colectiva asegurándoles financiamiento, capacitación y asistencia técnica. El objetivo mayor fue alcanzar la seguridad alimentaria, el mismo objetivo que ahora en el LGDESN 2007-2013 se contempla para la revolución agraria.

A partir de estas orientaciones, las iniciativas e inversiones públicas vinculadas al campo y todas las actividades conexas a ella incluyendo la agroindustria, han sido permanentes y con considerables aportes financieros (López Maya y Lander, 2009). A inicios de 2008, en el contexto de la fuerte alza de los precios petroleros en el mercado internacional, se profundizó el apoyo al sector, con la mirada puesta tanto en la seguridad alimentaria como en el desarrollo rural integral. Así mismo, a través del Plan Deuda Cero, el Gobierno condonó la deuda agrícola contraída por los productores entre 2000 y 2004 con el Fondo de Desarrollo Agropecuario, Pesquero, Forestal y Agrícola (FONDAFA), que es el brazo público financiero más importante para el sector agrícola (BCV 2009: 8).

En consultas hechas para este análisis con Juan Luis Hernández ${ }^{18}$ nos fueron proporcionados datos que evidencian cómo los esfuerzos realizados han derivado en resultados magros para este sector y en general para el logro de los objetivos del desarrollo rural integral. Pareciera transitarse un proceso similar al vivido durante el boom petrolero de mediados de los años setenta, bajo el gobierno de Carlos Andrés Pérez, cuando buena parte de los esfuerzos no produjeron mejorías significativas en la producción de alimentos, ni en las condiciones de vida en el campo. El país continuó, igual que ahora, dependiendo de las importaciones para alimentarse.

Señala Hernández, que desde el punto de vista de la superficie afectada, hasta 2008 cerca de 2 millones de hectáreas habían pasado a manos del Instituto Nacional de Tierras (INTI), lo que representa el 31\% de las tierras calificadas de lati- 
fundio por esa institución. Se trata principalmente de tierras para la ganadería extensiva, que no tienen mayor impacto en la producción agrícola, aunque si tienen efectos simbólicos importantes por ser tierras pertenecientes a lo que los chavistas llaman las oligarquías. Por otra parte, según el Instituto Nacional de Estadísticas (INE), los ocupados en la agricultura no han aumentado sino disminuido en términos absolutos en los tres últimos años. Mientras que en 2001 el número de jefes de familia ocupados en el campo fue de 850.165, en 2008 alcanzó la cifra de 965.531 pasando por un máximo en el año 2005 de 1.090 .708 (INE, 2009, Indicadores de Fuerza de Trabajo).

El financiamiento a los pequeños productores y a las formas asociativas estimuladas por el Estado como los saraos, fundos zamoranos y los NUDES ha sido muy considerable a lo largo de estos años. No obstante, muchos de los créditos otorgados no fueron destinados a la producción. Además, según el FONDAFA, el monto de los créditos no recuperados pasó de poco más de 200 mil millones de bolívares en 2005 a cerca de 740 mil millones en 2006, pasando del 18 al 65\% del total de la cartera de créditos. Hernández señala que la información disponible sobre la distribución de las tierras recuperadas por el INTI hasta 2008 indica que sólo el 9\% (168 mil has.) ha sido entregada a fundos zamoranos, mientras el 59\% es explotada individualmente. Sobre las cooperativas, las mismas fuentes oficiales señalan que sólo un $30 \%$ de las cooperativas están activas. ${ }^{19}$

Sirvan estos indicadores para dar muestra de la precariedad hasta 2008 del desarrollo de la revolución agraria emprendida a lo largo de estos años por el Gobierno. Concurren un conjunto de factores que permiten explicar por qué esto ocurre. En primer lugar, el desorden institucional. Muchas instancias sin la debida coordinación entre ellas tienen responsabilidades en el sector. Para ilustrar, FONDAFA comenzó adscrito al Ministerio de Agricultura y Tierras (MAT), luego pasó al Ministerio de Finanzas, regresó al MAT para luego ser transferido al Ministerio del Poder Popular de la Energía y el Petróleo y volver recientemente al MAT. Por otra parte, tampoco se han compatibilizado dos objetivos estrechamente vinculados entre sí como son la producción agrícola y la seguridad alimentaria. En procura de la segunda se hacen importaciones compulsivas que afectan negativamente al sector agrícola nacional. El agrícola es un sector complejo, más aún en un país de economía moldeada por la renta petrolera. Muchas iniciativas y medidas no parecieran responder a una comprensión cabal de esa complejidad. Y un aspecto que pareciera absolutamente crucial para alcanzar el buscado desarrollo rural integral es producir estrategias sostenidas de corto, mediano y largo plazo, para la capacitación, formación e inculcación de valores cónsonos con los objetivos del modelo socialista. En una sociedad marcadamente urbana y consumista es un desafío de grandes proporciones.

Otro proceso que se aceleró en los últimos años, particularmente después de la victoria del referendo sobre la enmienda constitucional, fue, como se señaló, el de las estatizaciones y expropiaciones. Sin intención de ser exhaustivos podemos señalar como ejemplos de estatizaciones después de ese referendo: a) en febrero de 2009, el Gobierno ordenó la intervención y control militar de empresas arroce- 
ras a las que acusó de responsables del desabastecimiento de ese producto, siendo la principal afectada Alimentos Polar; b) en marzo, Chávez ordenó expropiar plantas procesadoras de arroz de la empresa estadounidense Cargill, a la que acusó de violar la ley de producción de alimentos con precios controlados. Ese mes también anunció que la aerolínea Aeropostal, intervenida en noviembre de 2008, se convertiría en empresa de propiedad social; c) en mayo fueron nacionalizadas 60 empresas de actividades petroleras complementarias (transporte, inyección de agua, vapor o gas) en el lago de Maracaibo. También anunció que había cerrado la negociación con el Grupo Santander para la adquisición del Banco de Venezuela; d) en septiembre expropió cuatro empresas de transporte de combustibles que operaban en los Estados Zulia y Lara; e) en octubre, decretó la adquisición forzosa del complejo turístico de la cadena Hilton en la isla de Margarita; f) en noviembre nacionalizó la empresa procesadora de café Fama de América; g) en diciembre, en medio de un desarreglo bancario con denuncias de corrupción, fueron intervenidas varias entidades bancarias y de seguros, así como algunas empresas vinculadas a las anteriores.

Entre las expropiaciones pueden señalarse: a) en marzo, la intervención de 1.500 has. de la papelera irlandesa Smurfit Kappa, para cambiarles de cultivo; b) en abril, la ocupación del Hato El Frío y en mayo el presidente Chávez expropió 10.000 hectáreas de latifundios en distintas partes del país para fomentar la producción de alimentos. Otro ejemplo fue el "rescate" en septiembre de 2.408 has. del valle del río Turbio, afectando al menos a 30 hatos y justificado por el ministro del Poder Popular para la Agricultura y Tierras porque: "El derecho a la alimentación del pueblo está por encima de la propiedad privada" (PROVEA, 2009: 178).

\section{Intolerancia, intimidación y amedrentamiento: un gobierno crecientemente re- presivo}

En clara contradicción con lo que fueron los años iniciales del gobierno de Chávez, cuando los principales indicadores registrados sobre derechos civiles experimentaron mejorías (PROVEA, varios años), en este segundo período se ha hecho crecientemente evidente el endurecimiento del gobierno con todo tipo de manifestaciones de descontento y crítica a su gestión y al proceso de cambios que adelanta. Los sindicalistas, los estudiantes, medios de comunicación con líneas editoriales opositoras y los partidos políticos de oposición han sido los más afectados. Señalemos algunos ejemplos recientes.

Con el anuncio de promover consejos de trabajadores como parte del Poder Popular en el socialismo del siglo XXI, el Gobierno ha venido expresando su deseo de que las organizaciones sindicales pierdan importancia. Especialmente afectadas han sido aquellos sindicatos que defienden abiertamente su autonomía frente al Estado patrón y critican el desempeño gubernamental. La discusión de contrataciones colectivas con el Estado y empresas dependientes de él viene siendo retrasada de manera sistemática. Según PROVEA, la violencia en el ámbito sindical viene repuntando significativamente, registrándose en 2009 el homicidio de 46 dirigentes sindicales, sin que las investigaciones adelantadas 
determinaran los responsables de estos actos, manteniéndose una flagrante impunidad.

Los estudiantes son otro sector afectado por la intolerancia del Gobierno. Las marchas estudiantiles que promovieron el voto negativo en el referendo de la enmienda constitucional de 2009, fueron respondidas en varias oportunidades con represión por parte de las autoridades. El 17 de enero, en una alocución televisada, el Presidente mandó a los cuerpos de seguridad a enfrentarlas "sin diálogo" y con "gas del bueno". En septiembre de ese año fue detenido por protestar contra la ley de Educación el estudiante de la Universidad Humboldt de Carabobo, Julio César Rivas. La Fiscalía le imputó cinco delitos: resistencia a la autoridad, uso de arma genérica, instigación a la guerra civil, instigación a delinquir y daños y asociación para delinquir. A finales de septiembre fue liberado, después de que un grupo de estudiantes de distintas universidades se instalara frente a la OEA y realizara una huelga de hambre que llevó cuatro días.

Otros casos emblemáticos de amedrentamiento a fuerzas de la oposición han sido la privación de libertad al ex ministro de Defensa general Raúl Isaías Baduel, acusado de corrupción administrativa durante el ejercicio de su cargo. El general, en 2007, se pronunció abiertamente en contra de la reforma constitucional y criticó el proyecto socialista del Presidente como una reiteración del capitalismo de Estado del presidente Pérez. En agosto de 2009 fue privado de libertad el prefecto de Caracas y presidente del partido opositor Alianza Bravo Pueblo, por supuestos hechos violentos ocurridos durante una marcha de los empleados de la Alcaldía Metropolitana de Caracas en rechazo a la ley Especial del Distrito Capital, que sustrajo atribuciones a esa instancia constitucional a favor de una autoridad designada por el Presidente.

Las acciones contra medios de comunicación privados con miras a ampliar el control mediático del gobierno han sido múltiples. La más emblemática ha sido el cierre de Radio Caracas Televisión en mayo de 2007. Este canal, el más antiguo y de mayor cobertura en Venezuela, estuvo comprometido con los hechos insurreccionales de la oposición en 2002 y 2003. Si bien el cierre se dio por procedimientos institucionales, su anuncio hecho por el Presidente, desde un cuartel y ataviado de militar, en enero de ese año, reflejó querer exteriorizar que era un acto de retaliación política. Otro canal de TV opositor, Globovisión, ha sido desde 2007 sometido a varios procedimientos administrativos con el argumento de que viola la Ley de Responsabilidad Social de Radio y Televisión. A inicios de agosto de 2009, treinticuatro emisoras de radio fueron sacadas del aire mediante procedimientos "legales". El presidente Chávez declaró con anterioridad, que una revisión hecha por CONATEL había "descubierto" que "centenares" de emisoras radiofónicas funcionaban de manera ilegal. Anunció que serían sacadas del aire y traspasadas sus frecuencias a emisoras afines al gobierno: "Esas emisoras nuevas que se van a crear (...) no son para dárselas a la burguesía, hay que crear una radio popular en manos del pueblo". ${ }^{20}$ 


\section{A modo de cierre: el gobierno de Chávez ante la crisis financiera mundial y la inestabilidad de los precios petroleros}

En 2008 una profunda crisis financiera mundial, cuyo epicentro se ubicó en la economía de EE.UU. asoló el planeta. Sin embargo, y pese a la alta vulnerabilidad de la economía rentista petrolera que caracteriza a Venezuela, hasta que no se realizó en febrero de 2009 el referendo a la enmienda constitucional, el discurso gubernamental se dirigió a convencer al país que la economía de Venezuela, por ser socialista, estaba blindada. Desde diciembre de 2008, sin embargo, los desajustes fiscales comenzaron a hacerse visibles en la postergación de pagos y en demoras para cumplir compromisos por parte del Gobierno. Cadivi, la oficina de control de cambio, anunció ese mes una reducción a la mitad en la cuota anual de dólares preferenciales para viajeros. PDVSA declaró al iniciarse 2009, la postergación de sus planes de expansión en el exterior (refinerías en Ecuador, Nicaragua y Cuba) y una reducción de su programa de inversiones de este año de $40 \%$ con respecto al plan original. ${ }^{21}$

Pasado el referendo y victorioso el presidente Chávez, anunció un conjunto de medidas que identificó como de "anti-crisis". En primer lugar, un reajuste del presupuesto de 2009, re-estimando el precio de referencia de la cesta petrolera venezolana para reducirlo de $\$ 60$ a $\$ 40$. Redujo así mismo el estimado de los volúmenes de producción de 3.300 .000 a 3.100 .000 b/d. A partir de este nuevo escenario se contempló en el presupuesto una reducción del gasto de $6,7 \%$; se elevó el Impuesto al Valor Agregado (IVA) del 9 al 12\%, se propuso una modificación de la ley de endeudamiento interno para el ejercicio fiscal de 2009 para elevar de BsF. 12 a 34 millardos, que fue incrementado a BsF. 37 millardos en la ley presentada a la AN ese mismo mes. Se anunció también la necesidad de disminuir los llamados gastos suntuarios (adquisición de carros, celulares, actualización de plataformas tecnológicas, etc.) y la próxima promulgación de una ley de emolumentos para la administración pública cuyo objetivo sería poner límites a los salarios percibidos por los funcionarios de más alto rango. ${ }^{22}$ En enero de 2010 estas medidas se mostraron insuficientes, y el Gobierno anunció una devaluación del bolívar fuerte con dos tasas cambiarias: una del $20 \%$ para importaciones gubernamentales y otra del $100 \%$ para importaciones del sector privado. Así mismo endureció aún más el otorgamiento de dólares a viajeros. Como ya se señaló, en 2009 el PIB fue recesivo en el orden del $-3,3 \%$. En el primer trimestre de 2010 esta tendencia regresiva continuó, cayendo el PIB a -5,8\% (INE, 2010). Estas iniciativas gubernamentales no atacan el problema estructural de la economía rentista venezolana; son paliativos en espera de la recuperación de los precios del petróleo en los mercados internacionales.

Desde 2009, la combinación de una transformación hacia un modelo socialista que pese a su derrota en 2007 continúa como una imposición desde arriba por el Presidente, con este contexto socioeconómico signado por indicadores recesivos, ha venido creando un creciente malestar social y político en diversos estratos sociales. Las dificultades de la gestión gubernamental se ven potenciadas por una administración enormemente ineficiente, que se caracteriza por una constante ro- 
tación de los miembros del gabinete Ejecutivo, obedeciendo estos cambios principalmente a criterios de lealtad al Presidente y no por la búsqueda de capacidades profesionales. Las políticas de estatización, nacionalización y expropiaciones han aumentado en estos últimos años el aparato estatal, acentuando su ya deficitaria capacidad de gestión con calidad, eficacia, eficiencia o transparencia. Son crecientes las denuncias por corrupción; las más importantes de ellas son la que se reveló en la crisis bancaria de diciembre de 2009, que comprometió a empresarios cercanos al poder y la de mayo de 2010 en torno al abandono y descomposición de toneladas de productos comestibles importados en las aduanas recentralizadas por el Gobierno.

En razón de todo esto, se evidencian en la sociedad un auge de las protestas de calle y señales de una creciente reorganización de las fuerzas políticas, con miras a expresar este malestar diverso y en aumento. Las fuerzas tradicionales de oposición al presidente Chávez han hecho, con cara a las elecciones parlamentarias del 26 de septiembre de 2010, importantes esfuerzos por construir una plataforma política alternativa, que sea creíble para sus bases y para los descontentos de las filas del oficialismo. Sus metas más inmediatas se centran en alcanzar acuerdos entre ellos para presentar candidatos unitarios atractivos que puedan llegar a la AN y quebrar la dominación aplastante que hoy detenta el oficialismo. Otras agrupaciones buscan romper la política de la polarización en esos comicios, llevando candidatos independientes y mensajes no polarizados. Una victoria del Presidente, dependiendo de su monto, contribuirá a la consolidación del avance del modelo estatista y antiliberal que se viene imponiendo, o mantendrá la inestabilidad y resistencias actuales a tal proceso. En cualquier caso, la recuperación de la $\mathrm{AN}$ como espacio de representación de la diversidad de sectores, organizaciones e intereses en la sociedad, que es inevitable si se mantienen las reglas institucionales, abrirá otra fase en la lucha por una transformación con democracia en este país petrolero.

\section{Referencias}

1. Sobre la llegada de Chávez al poder, visto como una ruptura populista en Venezuela puede verse López Maya y Panzarelli (en prensa).

2. Siglas de la Comisión Presidencial de Reforma del Estado.

3. Las descripciones sobre estos hechos insurreccionales de la oposición son extractos de López Maya (2006).

4. Esta parte se apoya en López Maya (2005).

5. Para esta parte nos apoyamos principalmente en: López Maya (2006) y Maingon (2006).

6. El "parlamentarismo de calle" es una modalidad de consulta a la población sobre leyes que se discuten en la Asamblea Nacional. Se suele hacer en plazas públicas los fines de semana.

7. En esta parte nos apoyamos en López Maya (2009).

8. Disponible en: http://www.mci. gob.ve/alocuciones/4/. Consultado el 26-05-07.

9. Estos resultados corresponden a los del Bloque A que incluyó todos los artículos propuestos por Chávez.

10. Para este aparte nos apoyamos en López Maya y Lander (2009).

11. Proyecto de reforma constitucional, 2007, propuesta de reforma al artículo 115.

12. Las 337 alcaldías incluyen las dos metropolitanas: Caracas y Alto Apure. Las alcaldías municipales son 335 . 
13. Para esta parte nos apoyamos en López Maya y Lander (2010).

14. El Nacional, 08/01/09.

15. El Nacional, 16/02/09.

16. CEPAL, 2009 (http://www.eclac.org/estadisticas/).

17. Para esta parte seguimos López Maya y Lander (2009).

18. Juan Luis Hernández, 2009: experto en materia agrícola, consultado el 13 de abril.

19. Provea (2008); Oscar Bastidas (2009), entrevista en El Nacional, 26/04.

20. Tal Cual, $22 / 07 / 2009$.

21. El Nacional, 27/01/09.

22. Hasta la fecha ha sido imposible que la AN apruebe esta ley, que significaría una desmejora importante de los ingresos de altas autoridades y funcionarios públicos.

\section{Bibliografía}

APORREA (2004), “Oposición desconocerá a autoridades del Consejo Nacional Electoral”, 25 de febrero. Disponible en: http://www.aporrea.org/. Consultado el 20 de marzo de 2004.

BCV (2006), Información Estadística. Disponible en: http://www.bcv.org.ve/. Consultado en 2006.

BCV (2009), Informe a la Asamblea Nacional sobre los resultados económicos del año 2008, Caracas, marzo. Disponible en: http://www.bcv.org.ve/. Consultado en abril de 2009.

CD (2003), Coordinadora Democrática. Agenda de reconstrucción de la República de Venezuela. Disponible en: www.acuerdosocial.com. Consultado en diciembre de 2003.

CNE (2007, 2008 y 2009), Resultados electorales. Disponible en: http://www.cne.gov.ve/. Consultado en diferentes años.

CRBV (2000), Constitución de la República Bolivariana de Venezuela, Caracas, Vadell Hnos. Editores. H. R. CHÁVEZ (2007), "Juramentación del Consejo Presidencial para la Reforma Constitucional y del Consejo Presidencial del Poder Comunal”, Caracas, Sala Ríos Reyna, Teatro Teresa Carreño, 17 de enero. Consultado en Internet en febrero.

- (2006), "Chávez llama a conformar el Partido Socialista", Caracas, 16 de diciembre. Disponible en: www.aporrea.org/ideología/n87995.html.

S. ELLNER (2003), "El sindicalismo frente al desafío del chavismo", en S. ELLNER y D. HELLINGER (eds.), La política venezolana en la época de Chávez, Caracas, Nueva Sociedad.

M. P. GARCÍA-GUADILLA (2003), "Politización y polarización de la sociedad civil venezolana: las dos caras frente a la democracia", XXIV Congreso de LASA, Dallas, Texas, 27 al 29 de marzo.

INE (2006, 2009 y 2010), Estadísticas. Disponible en: http://www.ine.gov.ve/. Consultado en diferentes años.

E. LACLAU (2005), La razón populista, México, Fondo de Cultura Económica.

S. LEVITSKY y R. KENNETH (2010), "Latin America's Left Turn: A Framework for Analysis" (inédito).

LGDESN (2001-2007): Líneas Generales del Desarrollo Económico y Social de la Nación 2001-2007.

Caracas, bajado en septiembre de Internet.

LGDESN (2007-13): Líneas Generales del Desarrollo Económico y Social de la Nación, 2007-2013. Caracas, septiembre, bajado de http://www.mpd.gob.ve/ en mayo de 2009.

L. E. LANDER (2003), “Gobierno de Chávez, ¿nuevos rumbos en la política petrolera venezolana?", en L. E. LANDER, Poder y petróleo en Venezuela, Caracas, Faces (UCV)-PDVSA.

L. E. LANDER y M. LÓPEZ MAYA (2005), "Referendo revocatorio y elecciones regionales en Venezuela: geografía electoral de la población", en Revista Venezolana de Economía y Ciencias Sociales, Vol. 11, № 1 .

(2008), "Venezuela: protesta popular y lucha contrahegemónica

reciente", en M. LÓPEZ MAYA, N. IÑIGO CARRERA y P. CALVEIRO (editores), Luchas contrahegemónicas y cambios politicos recientes en América Latina, Buenos Aires, CLACSO.

M. LÓPEZ MAYA (2006), "Venezuela 2001-2004: actores y estrategias en la lucha hegemónica", en G. CAETANO (ed.), Sujetos Sociales y nuevas formas de protesta en la Historia Reciente de América Latina, Buenos Aires, CLACSO. 
M.LÓPEZ MAYA (2005), Del Viernes Negro al Referendo Revocatorio, Caracas, Grupo Alfa.

(2004), "Venezuela 2001-2004: actores y estrategias", en Cuadernos del Cendes, № 56, mayo-agosto.

Caracas, Año 2, № 5 .

(2003), "Las manifestaciones territoriales de la polarización”, El Punto Medio, (2002), "Venezuela: el paro cívico del 10 de diciembre", en Nueva Sociedad, $\mathrm{N}^{\circ}$ 177, enero-febrero.

M. LÓPEZ MAYA y A. PANZARELLI (en prensa), "Populismo, rentismo y socialismo del siglo XXI: el caso venezolano", Washington, ponencia presentada en la Conferencia Populism of the Twenty First Century (Woodrow Wilson Center), 8 de octubre.

M. LÓPEZ MAYA y L. E. LANDER (2010), "Venezuela 2009: en medio de dificultades avanza el modelo socialista del presidente Chávez", Revista de Ciencia Política, Santiago, Vol. 30, № 2.

(2009), "El socialismo rentista de Venezuela ante la caída de los precios internacionales", Cuadernos del Cendes $\mathrm{N}^{\circ} 71$, mayo-agosto.

(2001), “Ajuste, costos sociales y la agenda de los pobres

en Venezuela: 1984-1998”, en E. SADER (comp.), El ajuste estructural en América Latina. Costos sociales y alternativas, Buenos Aires, CLACSO.

T. MAINGON (2006), "El Estado de bienestar social en Venezuela: el caso de las misiones sociales", en Ágora, $\mathrm{N}^{\circ} 14$.

OJO ELECTORAL (2009), Informe final. Observación referendo de la propuesta de enmienda constitucional. Disponible en: http://www.ojoelectoral.org/comunicados.php. Consultado en abril de 2010.

D. PARKER (2002), "Debilidades en la conducción política del proceso también facilitaron el golpe", Observatorio Social de América Latina, $\mathrm{N}^{\circ} 7$, junio.

PROVEA (años citados), Situación de los derechos humanos en Venezuela. Informes anuales. Caracas.

Recibido: 15/05/2010. Aceptado: 10/08/2010.

Margarita López Maya, “Venezuela: once años de gestión de Hugo Chávez Frías y sus fuerzas bolivarianas (1999-2010)". Revista Temas y Debates. ISSN 1666-0714, año 14, número 20, octubre 2010, pp 197-226. 